\title{
Agricultura e Mercado de Trabalho: Trabalhadores Brasileiros Livres nas Fazendas de Café e na Construção de Ferrovias em São Paulo, 1850-1890
}

\author{
- MARIA LÚCIA LAMOUNIER*
}

\section{RESUMO}

Este artigo examina o emprego de trabalhadores brasileiros livres em diversas atividades nas fazendas de café e na construção de ferrovias em São Paulo na segunda metade do século XIX. A historiografia sobre o tema ressalta, em geral, a ausência/marginalidade dos trabalhadores nacionais na economia agroexportadora, seja assumindo a exclusão dos trabalhadores brasileiros considerados "vadios" e "indolentes" pela sociedade contemporânea, seja privilegiando os aspectos culturais desse grupo de população que resistia em se submeter aos novos moldes de dominação e padrões de eficiência e disciplina impostos neste momento de transição para o trabalho livre. Destacando o engajamento dos trabalhadores brasileiros nas mais diversas tarefas dos dois setores e a peculiaridade do emprego nessa economia rural baseada no trabalho escravo, o texto argumenta que, na verdade, era justamente a incapacidade da agricultura de gerar emprego durante todo o ano que produzia um padrão de instabilidade e mobilidade geográfica no mercado de trabalho rural, irregularidade/instabilidade que muitos identificavam como ociosidade e justificavam o recurso a legislações repressivas.

\section{PalavRAS-CHAVE}

ferrovias, fazendas de café, trabalhadores nacionais, trabalho, São Paulo

\begin{abstract}
This article examines the engagement of Brazilian workers in several tasks in railway building and coffee plantations in São Paulo during the second half of the nineteenth century. In general, most of historiography argues that nacionais lived a marginal existence, either due to the prejudice of contemporary Brazilian society against free poor people, invariably presented as "indolent", "vagrant" and "lazy"; or to the free people's resistance to the shift from cultural practices based on traditional values, to a more disciplined, methodical labour life. In contrast to these views, first, this article stresses the presence of Brazilian workers in the activities of both railway building and coffee plantations. Second, the article maintains that, in fact, it was the failure of agriculture to generate year-round employment that produced a pattern of instability and geographical mobility, that many (planters, officials and railway entrepreneurs) interpreted as an indication of worker indolence or cultural bias against regular employment, and asked for harsh social legislation against the poor workers.
\end{abstract}

\section{KEY WORDS}

Railways, coffee plantations, Brazilian workers, labour, São Paulo

\section{JEL CLASSIFICATION}

N36, N56, N96

\footnotetext{
* Agradeço a leitura e os comentários de Renato Perim Colistete. Agradeço também o apoio financeiro da FAPESP.

* * Professora do Departamento de Economia, Faculdade de Economia, Administração e Contabilidade de Ribeirão Preto (FEA-RP/USP). E-mail: lucialamounier@fearp.usp.br. End. para contato: Depart. Economia - FEA-RP/USP. Av. dos Bandeirantes, 3900 - Ribeirão Preto - SP - CEP 14040-900.

(Recebido em dezembro de 2005. Aceito para publicação em agosto de 2006).
} 
O objetivo deste artigo é examinar o emprego de trabalhadores brasileiros livres em diversas atividades nas fazendas de café e na construção de ferrovias em São Paulo na segunda metade do século XIX. Nesse período de rápida e crescente expansão da produção cafeeira, de corte no suprimento tradicional de braços e de desagregação das relações escravistas, a solução do problema da mão-de-obra envolvia a busca de fontes alternativas de trabalhadores e de novas formas de reorganização das relações de trabalho. Apesar de freqüentemente mencionado na historiografia como elemento importante na composição da população, seja no período colonial ou imperial, aparecendo nos altos e baixos da produção açucareira, cafeeira, algodoeira e outras, o trabalhador brasileiro livre e pobre tem sido objeto de poucos estudos. Em célebre artigo publicado há mais de vinte anos, Peter Eisenberg notou essa lacuna e sugeriu temas de pesquisa que resgatassem esses "homens esquecidos" do limbo em que os deixara a historiografia. (Eisenberg, 1989).

Em geral, a historiografia sobre o tema ressalta a ausência ou marginalidade dos trabalhadores nacionais na economia agroexportadora. Uma parte da literatura, ao utilizar conceitos como "marginalidade" e "desclassificação", procura mostrar a ausência e a recusa ao trabalho por parte dos brasileiros, que passivamente se colocariam à parte de uma ordem que não os incorporava. Alguns estudos, ao assumirem que os nacionais teriam vivido à margem da sociedade, chamam a atenção para o preconceito da sociedade brasileira contemporânea contra a população mestiça, livre e pobre, invariavelmente apresentada como "indolente", "vadia" e "ociosa". Tal preconceito, por sua vez, explicaria a preferência dos fazendeiros pelos imigrantes. ${ }^{1}$

Outros estudos procuram examinar as atitudes da população livre e pobre com relação ao trabalho em uma sociedade escravista e em um país com uma fronteira aberta, atitudes que revelariam a resistência desses trabalhadores em mudar um modo de vida baseado em valores culturais tradicionais para um outro mais metódico e disciplinado. A recusa ao trabalho, em vez de expressar o caráter indolente do brasileiro, revelaria o caráter independente e autônomo desses indivíduos. ${ }^{2}$ Como argumenta Sheila Faria (1998, p. 102) ao examinar a população livre e pobre no período colonial, mover-se em busca de melhores condições de vida era uma atitude previsível e esperada - e para os forros e seus descendentes identificava-se com o exercício da liberdade.

Assim, seja vendo os nacionais como alvos de políticas e ações de exclusão, seja conferindo maior autonomia aos trabalhadores nacionais em suas decisões e opções, o que fica patente é que para boa parte da historiografia esse grupo de população, apesar

1 Ver, entre outros, Franco (1997), Kowarick (1987), Azevedo (1988) e, mais recentemente, Leff (1997).

2 Ver, para o período imperial, Castro (1987 e 1995) e Moura (1996); para o período colonial, ver Souza (1982). 
de constituir mão-de-obra em potencial, não se tornou um elemento importante na formação do mercado de trabalho na segunda metade do século XIX.

Este artigo apresenta evidências que levam a conclusões distintas das apresentadas anteriormente. A maior parte dos estudos sobre os trabalhadores nacionais livres e pobres falha em não reconhecer as circunstâncias econômicas e sociais em que eles estavam imersos. Em particular, tais estudos não levam em conta que a sazonalidade do emprego era a principal causa da instabilidade e irregularidade da força de trabalho. ${ }^{3}$ Em uma sociedade predominantemente agrária, era normal não haver emprego disponível ao longo do ano para toda a população. A natureza sazonal, de curto prazo, do emprego nessa economia rural baseada no trabalho escravo, favorecia a mobilidade geográfica dos trabalhadores, os arranjos temporários e a ampliação do leque de atividades remuneradas procuradas pelos trabalhadores brasileiros - irregularidade e instabilidade que muitos identificavam como ociosidade e justificavam o recurso ao trabalho escravo, ao imigrante e a legislações repressivas.

De maneira distinta da que afirma a maior parte da literatura sobre o tema, este artigo destaca a presença marcante de trabalhadores brasileiros exercendo as mais diversas atividades nos dois setores. Além disso, ressalta-se a importância da produção de subsistência para os trabalhadores, que muitas vezes abandonavam o emprego para se dedicar à produção de gêneros alimentícios, cultivados em lotes próprios, arrendados, ou cedidos "de favor". A produção para a subsistência constituía uma garantia de independência, mas principalmente de sobrevivência, em uma economia basicamente agrária. A seguir, esses argumentos são desenvolvidos em duas seções: a primeira examina os trabalhadores brasileiros livres nas fazendas de café de São Paulo e a segunda examina os trabalhadores que eram empregados nas obras de construção das ferrovias. A última seção resume as principais conclusões do texto.

\section{OS TRABALHADORES NACIONAIS NAS FAZENDAS DE CAFÉ}

O crescimento da população livre brasileira foi contínuo ao longo do século XIX. A reprodução natural, a emancipação de escravos e a imigração contribuíram para que o número de pessoas livres fosse sempre maior que o número de escravos em quase todas as províncias do Império, desde o início do século XIX. Em São Paulo, apesar do incremento da população escrava até a década de 1880, provocado pela rápida expansão cafeeira, o número de escravos não atingia mais do que $30 \%$ da população

3 Examinando características similares nos Pampas, Samuel Amaral analisa a mobilidade geográfica (instabilidade) do trabalho como um reflexo da natureza sazonal, de curto prazo, na economia rural de Buenos Aires. Segundo o autor, a demanda é que era instável e não a fonte de trabalho. Ver Amaral (1998, p. 170-171). 
total. De acordo com Eisenberg, até nas zonas mais produtivas do café, no Vale do Paraíba e no Oeste Velho, a população livre constituía a grande maioria. ${ }^{4}$

Os trabalhadores livres e pobres, brancos ou negros, desempenhavam as mais diversas atividades e ocupavam-se dos mais diversos ofícios urbanos e rurais. Eram agregados, camaradas, empreiteiros, pedreiros, carpinteiros, pequenos sitiantes, vendedores ambulantes, vendeiros, empregados das tropas e da construção de estradas de ferro, entre outros. Como pequenos proprietários, esses indivíduos trabalhavam muitas vezes temporariamente, ou por empreitada, nas fazendas de café da vizinhança. Politicamente dependentes dos fazendeiros, esses trabalhadores sobreviviam de favores, trocados por votos, trabalho e proteção, por exemplo. Os pequenos lavradores, além de alugarem seus serviços, estabeleciam relações de trabalho com outros indivíduos, que muitas vezes não possuíam recurso algum. Geralmente contratavam camaradas que os ajudavam em períodos de muito trabalho. (Moura, 1996, p. 37).

Aqueles que não eram proprietários eram admitidos nas fazendas como agregados, tinham acesso a terras marginais, onde podiam plantar para sua subsistência. Em troca, eles desempenhavam diversas atividades, ligadas à produção, administração, supervisão e proteção das fazendas. Os nacionais podiam também ser empregados como camaradas, trabalhadores independentes, contratados por empreitada, locação de serviços ou diaristas. Além dos trabalhos na produção e cultivo do café, podiam derrubar matas e limpar o terreno para o plantio, construir e conservar os caminhos e estradas, cuidar do transporte local do produto, ajudar em época de colheita, cultivar gêneros de subsistência para a fazenda. Esses trabalhadores e suas famílias constituíam um potencial significativo de mão-de-obra que era recrutada nos momentos de pico do trabalho, para atividades que colocassem em risco a vida dos escravos ou que não eram do interesse dos imigrantes.

É difícil estimar a quantidade de trabalhadores brasileiros empregados nas fazendas de café. Mas o seu número nas mais diversas modalidades de arranjos de trabalho parece ter sido bastante significativo e claramente aumentou com o alargamento da fronteira agrícola e com a expansão das plantações de café. No município de Rio Claro, por exemplo, em 1822, de um total de 224 propriedades rurais, 151 (67,4\%) eram de proprietários que lavravam terras próprias, e a grande maioria sem escravos (120). O restante, $73(32,6 \%)$ propriedades, era ocupado por rendeiros, agregados, colonos e outros; em geral, famílias pobres demais, instaladas em minifúndios, que não podiam prover rendas, nem mesmo subsistência. Em 1857, ainda em Rio Claro, de um total estimado de 820 propriedades, $448(54,6 \%)$ eram de proprietários que lavravam terras próprias, a grande maioria sem escravos (393). O número de propriedades ocupadas

4 Eisenberg (1989, p. 224-225). De acordo com Herbert Klein (1972, p. 314), a população livre brasileira cresceu vigorosamente nas regiões cafeeiras de São Paulo e Rio de Janeiro. 
por rendeiros, agregados, colonos e outros aumentou para 372 , perfazendo um total de $45,4 \%$. Warren Dean observou que na década de 1850 o surgimento de um grande número de minifúndios indica que muitos pequenos proprietários estavam sendo marginalizados: eles deixaram de produzir gêneros para o mercado e passaram a trabalhar em tempo parcial nas fazendas. (Dean, 1977, p. 33-34).

É a partir de meados da década de 1850 , com a extinção do tráfico internacional de escravos e depois das primeiras experiências frustradas com imigrantes europeus, que os fazendeiros passam a ver os trabalhadores brasileiros como uma fonte viável de mão-de-obra alternativa ou complementar ao trabalho escravo, especialmente nas regiões de fronteira. Além de mais numerosos, a partir de meados do século os trabalhadores brasileiros passaram a estabelecer com as fazendas um relacionamento em bases mais precisas, mais previsíveis, constituídas por contratos escritos. Parece evidente que as experiências com os trabalhadores imigrantes, com o regime de parceria e outras modalidades de contratos, devem ter influenciado essa tendência. Como observou Floriano de Godoy, uma das principais conseqüências da "colonização particular" em São Paulo foi "chamar familias brasileiras para o trabalho agricola, submetendo-as ao regime das colônias." (Godoy, 1875, p. 133). Em 1859, o presidente da província de São Paulo sugeriu em seu relatório que brasileiros livres eram a melhor solução para o problema dos "braços para a lavoura" e pediu apoio para a promoção de recrutamento local. ${ }^{5}$

Evidências esparsas revelam alguns números e arranjos feitos com brasileiros livres pelos fazendeiros paulistas na década de 1850. Em 1853 a colônia da fazenda Morro Grande, na região de Rio Claro, empregava 23 imigrantes portugueses e 17 brasileiros. Em 1857 a colônia já tinha 24 portugueses e 43 brasileiros. Sublinhando os problemas e conflitos com os trabalhadores imigrantes, o proprietário João Ribeiro dos Santos relatou em 1859: "as familias ou individuos brasileiros que compõem a colônia estão submetidos ao mesmo regime de parceria tal como os imigrantes e as dividas daqueles são menores; eles pagam os seus débitos mais facilmente e aumentam suas economias." Em 1856, a colônia Boa Vista de Benedito Antônio de Camargo, em Rio Claro, empregava 42 brasileiros num total de 228 colonos. Camargo tinha começado sua colônia apenas com imigrantes portugueses, mas em 1857 deu início ao engajamento de famílias brasileiras, garantindo-lhes um lote de terra para o plantio de gêneros de subsistência. Em troca, as famílias deviam cuidar dos pés de café (carpir) e ajudar na colheita. ${ }^{7} \mathrm{Em}$

5 Discurso com que o Illmo. Excmo. Sr. Senador José Joaquim Fernandes Torres, presidente da provincia de São Panlo, abrio a Assembléa Legislativa Provincial, 1859. São Paulo: Typ. Joaquim Azevedo Marques, 1859, p. 19. A mesma sugestão foi feita no relatório, Discurso com que o Illmo. Excmo. Sr. Senador José Joaquim Fernandes Torres abrio a Assembléia Legislativa Provincial de São Paulo, 1860. São Paulo: Typ. Joaquim Roberto de Azevedo Marques, 1860, p. 14.

6 Arquivo Público do Estado de São Paulo [APESP]. Manuscritos, Colônias. Ordem 7213, caixa l (18271858), pasta Piracicaba.

7 APESP. Manuscritos, Colônias. Ordem 7213, caixa 1, (1827-1858), pasta Limeira. 
1855, as colônias de Souza Queiróz, em Limeira, possuíam 87 brasileiros e em 1857 chegaram a 305 brasileiros num total de 625 colonos. Souza Queiróz adotava contratos de parceria e de locação de serviços. ${ }^{8}$ Ao final da década de 1870 , nas fazendas São Gerônimo e Cresciúmal, propriedades do Barão de Souza Queiróz em Limeira e Pirassununga, havia 688 trabalhadores livres, incluindo 339 brasileiros; na colônia Santa Bárbara, também propriedade do Barão em Limeira, havia 304 trabalhadores livres, dentre os quais 250 brasileiros. ${ }^{9}$

De acordo com um relatório enviado ao presidente da província em 1854, São Paulo contava com 2.618 fazendas de café, que empregavam 55.834 escravos, 2.519 colonos e 4.223 agregados. O mesmo relatório estima que havia na província 667 engenhos de açúcar, empregando 15.641 escravos, 10 colonos e 698 agregados; e ainda 532 fazendas de gado, empregando 4.342 escravos, e 1.767 agregados. ${ }^{10}$ Quando de sua viagem às províncias do Rio de Janeiro e São Paulo, no início da década de 1860, o cônsul suíço Tschudi encontrou colonos brasileiros entre os parceiros de várias fazendas de café. (Tschudi, 1953, p. 159 e p. 186). Em 1872, em um dos maiores distritos cafeeiros, Rio Claro, cerca de 1.700 pessoas livres, entre agregados e sitiantes, eram empregadas nas fazendas da região, enquanto o número de escravos era de 2.753 . Em 1876, 45 fazendas em Rio Claro empregavam trabalhadores livres e escravos; 22 empregavam apenas escravos. (Dean, 1977, p. 123).

A partir de meados da década de 1870, há claramente um aumento do número de brasileiros empregados nas fazendas. Além da aprovação da Lei do Ventre Livre em 1871, que instaurou o processo de emancipação gradual dos escravos e tornou mais premente a busca de alternativas ao trabalho escravo, o dinamismo que a expansão cafeeira imprimia à economia de São Paulo e a ampliação da fronteira atraíam pessoas de várias regiões do País para a província.

A contribuição da migração interna para o aumento da população nas regióes cafeeiras ainda é uma incógnita. Warren Dean observou o relativo esquecimento das correntes migratórias internas pela bibliografia e, referindo-se à região cafeeira, afirmou que: "a migração interna de trabalhadores livres de outras provincias constituia um fator tão constante do crescimento das fazendas que é surpreendente que tenha recebido tão pouca atenção." Segundo o autor, o contingente de brasileiros em Rio Claro era heterogêneo, composto, inclusive, por migrantes que fugiam da grande seca nas províncias do Nordeste. Em torno de três mil desses migrantes se fixaram no oeste paulista entre

8 APESP. Manuscritos, Colônias. Ordem 7213, caixa 1 (1827-1858), pasta Piracicaba.

9 Relatório do Ministerio da Agricultura, Commercio e Obras Publicas. Rio de Janeiro: Typ. Americana, 1879 , p. 74-75.

10 Quadro estatístico de alguns estabelecimentos ruraes da província de São Paulo, organizado pelo Brigadeiro José Joaquim Machado de Oliveira. In: Discurso com que o Sr. Dr. José Antonio Saraiva abrio a Assembléa legislativa da provincia de São Paulo, no dia 15 de fevereiro de 1855; (Taunay, 1939, p. 134). 
1877 e 1878, sendo que mais de 600 foram contratados pela fazenda Angélica. (Dean, 1977, p. 118-119).

Examinando a região de Campinas, Denise Moura observa que desde meados de 1850 a presença do migrante foi delineando aos poucos os traços sociais e cotidianos da cidade. Segundo a autora, a intensificação do fluxo migratório para essa região só ocorreu a partir de meados da década de 1870. Entre 1854-1874, Campinas recebeu em torno de 9.000 pessoas, "número superior ao número de imigrantes". O progresso ocorrido com a expansão cafeeira e a multiplicação das atividades urbanas e rurais atraíram famílias e indivíduos de municípios das regiões do Rio de Janeiro e Minas Gerais. (Moura, 1996, p. 116). José de Souza Martins (1990, p. 71) também observa que vieram centenas de baianos para São Paulo com a obrigação de plantar café na fazenda Guatapará. Manuscritos do Arquivo do Estado revelam numerosas listas de retirantes nordestinos que vinham para São Paulo fugindo da seca e em busca de melhores oportunidades de trabalho. ${ }^{11}$ Listas de dezenas de famílias de retirantes cearenses foram remetidas ao Agente de Colonização em 1878 solicitando passagens e seu encaminhamento a diversos pontos da Província de São Paulo, incluindo Capivari, Amparo, Tatuí, São Bernardo, Cordeiro e Campinas, dentre outros. (Lamounier, 1988, p. 127).

À medida que se adentra na região de fronteira - São Carlos, Araraquara, Ribeirão Preto e outras -, a presença do brasileiro, especialmente do migrante, fica ainda mais marcante. Os migrantes ocupavam-se das mais diversas atividades na derrubada das matas, na formação dos cafezais, na colheita, na cultura de subsistência, no transporte dos gêneros, na conservação e manutenção das estradas, na construção civil e em várias atividades urbanas. Ao lado dos migrantes que se estabeleciam, havia os migrantes de passagem, seja por ocuparem profissões que os obrigavam a estar em trânsito, como cocheiros, tropeiros e carroceiros, seja por estarem em busca de outras terras, na fronteira. Enquanto não partiam também desempenhavam tarefas, por empreitada, por exemplo.

Durante a maior parte do século XIX, as referências aos trabalhadores brasileiros sempre foram negativas. Eles eram geralmente caracterizados como indolentes e preguiçosos. Há, no entanto, uma mudança no tom das declarações, especialmente as oficiais, a partir das décadas de 1860 e 1870 . Em São Paulo, muitos políticos e fazendeiros passaram a sugerir e recomendar os trabalhadores brasileiros, como uma alternativa viável à escravidão. Os brasileiros passaram a ser vistos como mais “à mão", solução mais imediata e mais barata para o problema tão urgente da mão-de-obra. Não se

11 Arquivo do Estado, Manuscritos, Solicitações de passagens ao Sr. Joaquim José do Rego Rangel, 1878. APESP, Ordem 7215, lata 3. Denise Moura (1996, cap. 4) dedica um capítulo de sua dissertação ao exame destas listas e ao trabalho dos cearenses nas fazendas de café. 
abandonavam os planos de imigração européia, mas achava-se que essa última era uma solução a ser implementada no longo prazo.

As opiniões divergiam com relação ao melhor modo de recrutamento e engajamento dos brasileiros. Muitos fazendeiros reclamavam da instabilidade, da falta de aplicação e regularidade dos trabalhadores brasileiros. Se os agregados, que conseguiam maior segurança com relação à posse de um lote de terra, tornavam-se mais confiáveis fornecendo mão-de-obra para as fazendas, o mesmo não se pode dizer dos camaradas. Os camaradas eram um elemento transiente entre a população livre, não possuíam garantias de acesso à terra e à proteção do fazendeiro do mesmo modo que os pequenos sitiantes ou agregados; por outro lado, sentiam-se mais livres para deixar o trabalho nas fazendas quando bem entendessem. Sempre havia a perspectiva de novas terras e de emprego em outros lugares. Aparentemente, parecia mais fácil para eles abandonar a fazenda, uma tendência que os proprietários percebiam como preguiça e imprevidência.

A insegurança das condiçóes em que viviam os camaradas também os tornava alvos mais fáceis de exploração. Evidentemente, sem a proteção de um proprietário poderoso podiam ser presos como vadios e obrigados a trabalhar em obras públicas. A preocupação com a vadiagem foi uma constante ao longo de todo o século XIX. Desde a elaboração do Código Criminal de 1830, uma série de leis, que incluíam posturas municipais e termos de bem-viver, assim como cláusulas específicas em legislações referentes a trabalhadores livres e em legislações gradualistas, buscava forçar livres pobres e ex-escravos ao trabalho. Para alguns fazendeiros, contratos de trabalho de longo prazo e legislações mais repressivas constituíam uma forma de assegurar disciplina e regularidade no trabalho. Para outros, contratos serviam para introduzir esses trabalhadores livres em formas diversas de relações de trabalho, ensiná-los noções de ética e disciplina de trabalho regular. (Lamounier, 1988).

Durante o Congresso Agrícola, realizado no Rio de Janeiro em 1878, os fazendeiros de café debateram várias propostas sobre o modo de encaminhar o problema da mãode-obra. As sugestões abrangiam o uso de imigrantes europeus e asiáticos, a criação de milícias rurais e a coerção de brasileiros por meio de contratos draconianos reforçados por legislações repressivas. A proposta de uma "Comissão nomeada pelos lavradores de São Paulo" favorecia claramente a promoção da imigração de europeus. A proposta aceitava também o engajamento de asiáticos como "um meio de transição". Na opinião da Comissão, os trabalhadores brasileiros eram "indolentes" e resistentes ao "trabalho regular”. (Congresso Agrícola, 1878, p. 75-77). Mas durante os debates, vários outros fazendeiros paulistas sugeriram e defenderam mecanismos que incentivassem os nacionais a fornecer trabalho mais regular e estável. Para o fazendeiro de Queluz, Manoel de Freitas Novaes, por exemplo, os trabalhadores brasileiros eram os melho- 
res. Ele se orgulhava de ter tido por quase vinte anos uma colônia só com "caboclos", que começou com quatro famílias (sem contratos) e que na época já contava "com 500 e tantos brasileiros, muitos deles filhos e netos dos primeiros colonos." Os trabalhadores da colônia encontravam-se sob os mais diversos arranjos de trabalho: parceiros (ou a meia) que eram pagos "no dia em que colbem o café", outros que entregavam o café preparado, e outros que eram pagos "a jornal ou empreitada". O fazendeiro acreditava que o trabalhador brasileiro era melhor que o estrangeiro, "porque entra no mato e, incólume, derruba as árvores; ao passo que o estrangeiro entra no sertão e fica inutilizado pelos insetos que o atacam.” (Congresso Agrícola, 1878, p. 139 e p. 160-161).

O fazendeiro de São Carlos do Pinhal, Francisco Geronymo Bittencourt Coelho, também relatou que seus trabalhadores eram, em sua maioria, brasileiros. (Congresso Agrícola, 1878, p. 168). Domingos José Nogueira Jaguaripe Filho, expressando a opinião dos membros do Cube da Lavoura (associação de fazendeiros) de Rio Claro, também defendia os trabalhadores brasileiros. Ele rejeitava fortemente as propostas de importação de imigrantes chineses contratados. Na verdade, Jaguaripe Filho declarava-se opositor de qualquer proposta de importação de imigrantes contratados. A melhor alternativa, a seu ver, era a imigração européia espontânea. No entanto, ele julgava que tal imigração ainda demoraria muito tempo para acontecer; em sua opinião, a solução para o problema que "era tão urgente" era a criação de "milícias agrícolas”, que reunissem os pobres dispersos pelo país. (Congresso Agrícola, 1878, p. 157-160).

Para muitos fazendeiros não havia escassez de trabalhadores. O problema da "falta de braços" não era demográfico, mas político; a questão era como mobilizar essa força de trabalho potencial que constituía a população livre e pobre brasileira. Apesar de mostrar-se uma alternativa viável ao trabalho do imigrante e ao trabalho do escravo, o emprego de trabalhadores brasileiros exigia reformas complexas, muitas delas controversas e de custos políticos e econômicos grandes. Havia uma forte resistência à isenção do serviço militar e não se confiava na eficácia de uma legislação contra a vadiagem.

Na opinião, por exemplo, de F. José de Queiroz e Moreira de Barros, da região de Taubaté, "se bem empregados" os braços existentes eram suficientes para sustentar o incremento e a rápida expansão da lavoura cafeeira. Argumentando a favor do uso de “aperfeiçoamentos modernos”, máquinas e novos instrumentos agrícolas, Moreira de Barros observava que os fazendeiros "precisam também aproveitar melhor os braços de que dispõem, e os processos usados em seus estabelecimentos agrícolas." Segundo Moreira de Barros, além do serviço da cultura de terras e da colheita de produtos, o agricultor precisava ainda de muitos jornaleiros para vários tipos de trabalho: limpar pastos, 
fazer derrubadas, construir açudes, matar formigas, secar café e outros serviços nos terreiros, beneficiar café, entre outros. Esses últimos não eram serviços prestados por colonos ou realizados por empreitada; mas mais adequados aos jornaleiros. Na época, segundo o relato, além dos escravos, utilizavam-se libertos nesses serviços. (Congresso Agrícola, 1878, p. 185-190).

Poucos meses depois da realização do Congresso Agrícola no Rio de Janeiro, uma nova legislação, a lei de locação de serviços de 1879, foi formalmente aprovada. O grande mentor da reforma, Nabuco de Araújo, havia completado seu projeto e participara dos debates na Câmara e no Senado, mas não sobrevivera para ver sua proposta definitivamente aprovada quase sem mudanças. O texto era bastante complexo e chegou-se a comentar que mais parecia um "código rural". A Lei dava providências para os contratos de trabalho efetivados especificamente na agricultura e ampliava garantias para os contratos com brasileiros, imigrantes e libertos, contratados sob vários sistemas, como a parceria, a empreitada e a locação de serviços.

A Lei de Locação de Serviços veio, evidentemente, complementar a Lei do Ventre Livre e prevenir os efeitos da implementação da política de emancipação gradual. Na época, rebeliôes escravas e greves de trabalhadores imigrantes estavam deixando os fazendeiros atônitos e preocupados. A Lei de 1879 era uma tentativa de incentivar várias categorias de trabalhadores a formalizar as relações que estabeleciam por meio de contratos, cujas condições seriam garantidas pela aplicação da lei e de suas penalidades para os infratores. A Lei estabelecia condições diferentes para os vários trabalhadores. Por exemplo, o prazo do contrato: 3 anos para imigrantes europeus, 5 anos para os brasileiros e 7 anos para os libertos. A Lei estabelecia sanções severas, como prisão e trabalho forçado, para aqueles que não cumprissem as condições dos contratos ou participassem de rebeliões e greves. (Lamounier, 1988, cap. 2). Paralelamente, o texto providenciava para que houvesse estrito controle sobre a mobilidade geográfica dos libertos e estabelecia sanções contra a vadiagem. ${ }^{12}$

Na época da aprovação da Lei de Locação de Serviços, a produção cafeeira em São Paulo estava em franca expansão. A quantidade de café exportada pelo Porto de Santos aumentara de 543.425 sacas em 1870 para 1.204 .328 sacas em 1880 ; em 1890, atingiu 3.048.327 de sacas. (Saes, 1996, p. 181). O número de quilômetros de trilhos de ferrovias construídos em São Paulo aumentara de $139 \mathrm{~km}$ em 1870 para $1.212 \mathrm{~km}$ em 1880, chegando, em 1890, a $2.425 \mathrm{~km}$. A expansão das ferrovias permitiu o alargamento da fronteira agrícola e a área plantada com café crescia rapidamente:

12 Decreto 2827, 15 de março de 1879. Colleç̧ão das leis do Imperio do Brasil, 1879. Rio de Janeiro: Typ. Nacional, 1861-1880. v. 1879, p. 11-20; Projeto n. 241, 1882, Anais do Parlamento Brasileiro, 19 de setembro de 1882 , p. 45-46, por exemplo. 
de 60.462.000 cafeeiros em 1870 para 69.540 .000 em 1880 e 106.300 .000 em 1890 . (Mattoon, 1977, p. 286).

Além da sazonalidade da agricultura, que regulava a oferta e demanda de trabalho, a expansão da malha ferroviária também afetava - mas de modo contraditório - a questão da mão-de-obra. Se, por um lado, as ferrovias contribuíam para reduzir a demanda de mão-de-obra, liberando trabalhadores engajados no antigo sistema de mulas, por outro, elas contribuíam para aumentar a necessidade de trabalhadores ao ampliar a fronteira agrícola, favorecendo a incorporação de novas terras para cultivo. Além disso, as ferrovias demandavam um grande número de trabalhadores para a sua construção. Para os trabalhadores engajados na construção das ferrovias, no entanto, as oportunidades oferecidas pelo setor pareciam se harmonizar com os interesses da agricultura de exportação, como será visto a seguir.

\section{OS TRABALHADORES NACIONAIS NA CONSTRUÇÃO DAS FERROVIAS}

As primeiras concessóes para a construção de ferrovias foram aprovadas em 1852, logo após a extinção do tráfico internacional de escravos. Entre 1854 e 1894 foram construídos $11.260 \mathrm{~km}$ de trilhos de ferrovias no País. Deste total, cerca de $26 \%(2.962 \mathrm{~km})$ foram construídos na província de São Paulo. (Matoon, 1977, p. 286). Nessa época, a grande expansão cafeeira em direção ao oeste gerava reclamações freqüentes sobre a "escassez de trabalhadores" e "falta de braços" para a lavoura.

A construção de uma ferrovia é uma tarefa complexa. Envolve grandes volumes de recursos financeiros, os mais diversos tipos de máquinas, engenheiros, uma quantidade relativamente grande de mão-de-obra qualificada e uma enorme quantidade de homens com nenhuma qualificação. No Brasil, assim como na maioria dos países no século dezenove, a construção de uma ferrovia baseava-se no sistema de empreitada. As companhias ferroviárias raramente empregavam diretamente os trabalhadores da construção. Eles eram engajados, supervisionados e pagos por pequenos empreiteiros locais, que contratavam com as companhias a construção de partes da linha. Por isso, os trabalhadores da construção não pertencem tecnicamente ao quadro dos empregados da empresa ferroviária e se diz que eles "merecem um tratamento diferenciado." (Licht, 1983, p. xvii). Vários estudos têm mostrado que os trabalhadores engajados na construção e manutenção do leito de ferrovias constituíam o maior número da força de trabalho, o que dependia da extensão da linha e da complexidade das obras. (Licht, 1983, p. 33; Ducker, 1983, p. 4).

A maior parte da literatura a respeito dos trabalhadores das ferrovias no Brasil concentrou-se nos trabalhadores que operavam as ferrovias, não existindo muitos estudos so- 
bre os trabalhadores que cuidavam da construção e manutenção dos leitos. A principal razão para essa lacuna reside, provavelmente, na grande dificuldade de rastreá-los nas fontes. Como aqueles trabalhadores não eram empregados diretamente pelas companhias, não aparecem em seus relatórios e documentos. ${ }^{13}$ Do mesmo modo, é difícil acompanhar o grande número de empreiteiros e subempreiteiros que empregaram a grande maioria desses trabalhadores. Os contratos eram temporários, podiam ser de longo ou curto prazo, variando de acordo com a complexidade dos trabalhos, com as tarefas e preços acertados, com os salários e - um ponto relevante - com os trabalhos sazonais na agricultura. (Lamounier, 2000).

A construção de uma ferrovia envolvia uma série de tarefas complexas. A completa ausência de mapas precisos e confiáveis tornava necessária a realização de levantamento geográfico e topográfico da área antes de se projetar a rota da ferrovia. Terminado o levantamento, podiam ser iniciados os trabalhos de construção, que incluíam derrubada da mata, preparação do terreno (drenagem de pântanos, movimentos de terra, incluindo escavações, transporte, depósito e outros), nivelamento do leito (o restante da terraplenagem, aterros e taludes e abertura de túneis), projetos de alvenaria (para reforçar taludes, túneis e pontes, construir as estações e depósitos) e assentamento da via permanente (dormentes, trilhos e lastro).

O trabalho nas ferrovias implicava mobilidade - a necessidade de mudar de acordo com o passo das obras. Significava igualmente isolamento, ou seja, viver longe das cidades, separados da família e amigos, normalmente em regiões distantes, na fronteira. Trabalhando em grupos, vivendo juntos em acampamentos ao longo da linha, dividindo ansiedades, perigos e doenças - tudo isso ajudava a criar laços especiais entre os trabalhadores. Ao mesmo tempo, as condições de trabalho eram precárias. A natureza e severidade do trabalho (especialmente a escavação, a construção de túneis e a construção de pontes) assim como as diferenças étnicas e a pobreza geravam conflitos dentro do grupo e entre as turmas de trabalhadores. A preocupação constante dos empreiteiros e engenheiros com a segurança nos acampamentos e a presença da polícia nos locais de trabalho atestam a frequiência dos conflitos. (Lamounier, 2000, p. 69).

A construção de ferrovias requeria um grande número de engenheiros e técnicos, trabalhadores qualificados e semiqualificados. A construção demandava um número ainda maior de trabalhadores não qualificados. Informações sobre o número e a origem dos trabalhadores engajados na construção das ferrovias são esparsas e raras. A historiografia em geral aceitou a tão comentada escassez de trabalhadores para a agricultura de exportação e assumiu que o mesmo problema afetava as companhias

13 Licht (1983, p. 32) comenta sobre as dificuldades de se conseguir dados sobre números de trabalhadores empregados nas ferrovias norte-americanas. $\mathrm{O}$ autor observa que antes de 1880 o censo federal contava apenas engenheiros, foguistas, condutores e guarda-freios como "ferroviários". 
ferroviárias. ${ }^{14}$ As evidências, no entanto, demonstram que as companhias ferroviárias estavam bem supridas de mão-de-obra. Havia escassez de trabalhadores apenas em regiões desertas como a Amazônia. Havia também falta de mão-de-obra para aquelas tarefas consideradas muito difíceis, árduas ou perigosas.

Em São Paulo, os empreiteiros encontraram uma força de trabalho que podia ser recrutada localmente e que podia ser rapidamente treinada para desempenhar tarefas semi-especializadas. Desde o começo, os construtores da São Paulo Railway relataram que "sobre a importante questão do suprimento de mão-de-obra as expectativas eram altamente animadoras." 15 Em 1861, em uma carta aos diretores, o empreiteiro Sharpe informou sobre sua chegada ao Brasil, observando que não tinha medo de não ser capaz de completar as obras no prazo estabelecido. Sharpe já tinha comprado uma propriedade perto da linha, "os prédios que seriam transformados em armazéns", e acrescentava que "não tinba experimentado a escassez de homens que se esperava" (grifo da autora). Os trabalhadores nativos eram mais tratáveis do que ele tinha imaginado e, segundo Sharpe, "eles vêm em tão grande número que ele tinha sido obrigado a recusar vários, considerando imprudente empregar mais do que ele presentemente já havia feito - cerca de 200.” Além disso, “... as obras estavam se tornando populares entre os trabalhadores nativos e a cada dia aumentava o número daqueles se inscrevendo para o trabalbo, de modo que não deverá haver falta de mão-de-obva"l6 (grifo da autora). Durante todo o ano de 1861 foi relatado que havia trabalhadores disponíveis.

Apesar destes relatos bastante confiantes, a disponibilidade de trabalho não qualificado aparece claramente relacionada à sazonalidade do ciclo agrícola. Em 20 de dezembro de 1861, de acordo com o relatório do engenheiro Brunlees, havia 2.271 homens e 280 cavalos empregados nas obras; além disso, "[c]omo a estação de plantio terminou o número de bomens aumenta diariamente ${ }^{17}$ (grifo da autora). Já em dezembro de 1862 havia 2.432 homens e 307 mulas e bois empregados nas obras. Brunlees afirma que em meados daquele ano houve "[e]scassez de trabalbadores devido aos homens partirem durante a estação de plantio" (grifo da autora). Segundo o relato, no entanto, os empreiteiros haviam tomado medidas efetivas para se assegurarem contra recorrências deste tipo de interrupção e "agora eles estão de posse de uma classe melhor de trabalhadores do que até então tinham de comandar."18

14 Vários autores chamam atenção para o problema da escassez de trabalhadores nas ferrovias; ver, entre outros, Costa (1976, p. 73); Mattoon (1977, p. 289); Cechin (1978, p. 42) e El-Kareh (1982, p. 77).

15 Railway Times (1860, p. 860).

16 Railway Times (1860, p. 896, carta de 4/07/1860).

17 Herapath (1862, XXIV, p. 132).

18 Herapath (1863, XXV, p. 125). 
Observadores contemporâneos e historiadores mencionam os bons salários pagos aos trabalhadores nas obras de construção. ${ }^{19}$ Bons salários eram evidentemente um forte atrativo, mas não o suficiente para manter os trabalhadores regularmente em suas atividades. De acordo com o relatório do cônsul britânico, durante uma parte do ano "nenhum incentivo em forma de altos salários consegue fixar os trabalhadores em um lugar distante de suas casas." ${ }^{20} \mathrm{O}$ engenheiro Fox observou atitudes similares nos trabalhadores na construção da São Paulo Railway. (Fox, 1870, p. 21-22).

O caráter sazonal do trabalho e o que parecia ser uma certa inabilidade de reter os trabalhadores causavam uma série de queixas dos empreiteiros e engenheiros. Há vários indícios de uma forte resistência dos trabalhadores em cortar os laços com os lotes de subsistência, retornando às suas casas durante a estação de plantio e colheita. Em relatório de 1859, um engenheiro observou o caráter sazonal da disponibilidade da "população nativa": "[o]s brasileiros nativos e os negros livres parecem bastante dispostos a trabalhar em certos periodos, mas apenas nestes periodos [...]; para cultivar seus próprios lotes nas estaçôes adequadas, eles abandonam todos os outros compromissos [...] e há época que ocorre uma superabundância de homens oferecendo seus serviços, apesar de nem sempre acontecer naquele momento em que eles são mais necessários." 21

Essa resistência do trabalhador em não comprometer a subsistência, no entanto, era muitas vezes vista como indolência, uma recusa em trabalhar. O engenheiro Fox da São Paulo Railway observou que os brasileiros eram "uma raça tratável, de fácil manejo, que prezava um tratamento gentil e atencioso... ." Contudo, eles tinham uma "indisposição para o trabalho, em parte pelo orgulho engendrado pela escravidão, e em parte pela indolência causada pela ausência de incentivos para o trabalho [...]." Fox reconhecia que "as sólidas vantagens do trabalho, na forma de bons salários, pagos regularmente levava alguns deles a deixar suas choupanas e pequenas plantaçôes de banana, feijão e milho, sempre, para voltar para casa na época do plantio" (Fox, 1870, p. 22) (grifo da autora). Essas percepções e preconceitos por parte dos engenheiros das ferrovias refletiam a visão dos proprietários e prefiguram afirmações freqüentemente repetidas na historiografia tradicional: a "indolência" de grande parte da população brasileira e seu pouco ou nenhum compromisso com o setor agroexportador.

Porém, as evidências revelam que uma forma de garantir o acessso à terra e à subsistência incluía o engajamento, ainda que precário, às atividades ligadas às grandes fazendas. Com a perspectiva do fim da escravidão, e o incremento no número de obras de construção ferroviária em São Paulo na década de 1870, passou a ocorrer competição pelo trabalho entre o setor agrícola e as empresas ferroviárias. A expan-

19 Referências sobre os altos salários das ferrovias aparecem em contemporâneos, como Soares (1860, p. 137) e Tschudi (1953, p. 109), e na historiografia, como, por exemplo, em El-Kareh (1982, p. 78).

20 Parliamentary Papers (Great Britain, 1865, LIII, p. 366).

21 Railway Times (1859, p. 1198). 
são da produção cafeeira requeria um número crescente de trabalhadores e se tornava cada vez mais freqüente o emprego de trabalhadores brasileiros livres nas inúmeras atividades necessárias para o funcionamento das fazendas cafeeiras. Como o trabalho era sazonal, muitos destes trabalhadores aproveitavam os altos salários nas obras de construção das ferrovias.

A documentação analisada não permite comprovar os diversos vínculos que esses trabalhadores estabeleciam com a terra. Alguns eram, provavelmente, pequenos proprietários em busca de complementação de renda, outros cultivavam lotes de subsistência em terras de outros (como meeiros, agregados) e outros talvez tivessem vínculos ainda mais precários, ocasionais. Ainda assim, alguns dados sobre a composição da população brasileira e de São Paulo no período podem fundamentar um pouco mais o ponto.

Em meados de 1870, a população brasileira era de 9.930.478, incluindo 1.285.496 escravos, ou seja, $12,9 \%$ do total. De acordo com o censo de 1872 , cerca de $40 \%$ da população brasileira estava engajada em atividades agrícolas, $1 \%$ no comércio e $0,19 \%$ na manufatura e 7,54\% eram compostos de mecânicos, carpinteiros, ferreiros, fabricantes de chapéus, entre outras funções. O censo também mostra que $42 \%$ da população total vivia sem uma ocupação definitiva. ${ }^{22}$ Um padrão semelhante era notado na província de São Paulo, ainda que nela houvesse relativamente mais escravos e menos trabalhadores sem ocupação definitiva do que no total nacional. Os dados fornecidos por Godoy mostram que a população total de São Paulo, em meados da década de 1870, era de 837.354 habitantes, dos quais $18,7 \%$ eram escravos. Do total da população, $32,1 \%$ se declararam "sem ocupação", correspondendo a 268.581 . (Godoy, 1875, p. 46).

O fato de indivíduos não possuírem ocupação, no entanto, não significava ausência de trabalho. Muitas vezes a falta de ocupação significava o engajamento em atividades temporárias, em serviço irregular e não permanente. Do ponto de vista da população livre, o engajamento em qualquer tipo de trabalho temporário era uma forma de manter a independência, diante de leis que podiam restringir sua autonomia e mesmo sua liberdade. De fato, leis contra a vadiagem puniam com prisão e trabalho forçado todos aqueles que não provassem que possuíam ocupação. As leis de recrutamento militar também providenciavam para que aqueles que não estivessem engajados em atividades da agricultura de exportação fossem alistados para a Guarda Nacional ou para o Exército (no caso da Guerra do Paraguai, 1865-1870). Como observado anteriormente, desde meados do século intensificaram-se as tentativas de controlar a população livre nacional estabelecendo leis repressivas baseadas em contratos de serviços

22 Parliamentary Papers (Great Britain, 1881, Parte I, p. 34). 
de longo prazo. As leis de locação de serviços eram consideradas um meio eficiente de garantir uma força de trabalho disciplinada, regular e estável. ${ }^{23}$

\section{CONSIDERAÇÕES FINAIS}

A historiografia sobre a inserção, papel e lugar dos trabalhadores livres brasileiros na sociedade agroexportadora durante o período de transição da escravidão para o trabalho livre tem freqüientemente ressaltado a ausência ou marginalidade dos trabalhadores brasileiros. Essa ausência ou marginalidade é explicada, em geral, pela atitude (deliberada ou não) de exclusão por parte do governo e de proprietários ou por uma atitude dos próprios trabalhadores que teriam se recusado a trabalhar em determinadas condições, como forma de garantir sua independência na sociedade escravista.

Este artigo apresentou evidências que questionam tais interpretaçôes predominantes na historiografia. As evidências mostram o engajamento dos trabalhadores brasileiros em duas atividades interligadas na crescente economia agroexportadora de São Paulo na segunda metade do século XIX: nas diversas tarefas exigidas pelas fazendas de café e nas obras de construção de ferrovias. Privilegiando o problema da mão-de-obra no momento de decadência das relações escravistas na segunda metade do século XIX, o artigo procurou examinar as inter-relações entre a expansão cafeeira e a expansão da malha ferroviária. Claramente, a expansão ferroviária intensificava o tão comentado problema da escassez de trabalhadores no período, seja ampliando a fronteira e a quantidade de terra cultivada, seja exigindo em suas obras um grande número de trabalhadores.

A natureza sazonal, de curto prazo, do emprego nessa economia rural baseada no trabalho escravo favorecia a mobilidade geográfica dos trabalhadores. O ciclo sazonal da agricultura condicionava a oferta de mão-de-obra para a construção das ferrovias assim como para outras atividades não rurais. $\mathrm{O}$ trabalho de construção da ferrovia veio representar mais uma fonte importante de emprego para milhares de brasileiros pobres que, mesmo tendo acesso à terra, cultivando lotes próprios ou de outros, necessitavam complementar a sua renda, e para milhares de outros que provavelmente tinham de deixar as fazendas no período de entressafra. Por sua natureza, o trabalho de construção oferecia um emprego temporário e obrigava os trabalhadores a mudar de um lugar para outro. Os trabalhadores "viajavam" com a linha à medida que a construção progredia e, caso tivessem sorte, conseguiam uma sucessão de contratos

23 Lamounier (1993, cap. 4). Amaral (1998, p. 46 e 177) observa que a repressão à vadiagem tinha como alvo restringir as atividades legais e ilegais dos trabalhadores livres, "without putting an end to them, since they were part of the informal agreements between landowners and free workers for protection and labour [...] Vagrancy was easy to see, but the identification of vagrant individuals was difficult." 
temporários. Desse modo, o trabalho na construção combinava com a precariedade e instabilidade dos empregos em uma sociedade essencialmente rural e escravista.

Apesar dos relativamente altos salários pagos pelos empreiteiros das ferrovias, era difícil reter os trabalhadores durante a época de plantio e de colheita. A resistência em abandonar os laços com a agricultura de subsistência (seja pelos cultivadores independentes ou por aqueles dependentes das fazendas para ter acesso a um pequeno lote de terra), em época de rápida transformação da sociedade brasileira, foi uma característica importante no período. Ecoando opiniões prevalecentes entre proprietários e oficiais do governo, os empresários das ferrovias muitas vezes interpretavam aquela relutância como um indicador da indolência do trabalhador ou de seu caráter avesso ao trabalho regular. Da mesma forma, a literatura tem examinado essa característica como uma expressão da indolência dos trabalhadores brasileiros ou, então, como uma forma de eles garantirem sua autonomia, independência, de se mostrarem diferenciados do trabalhador escravo, ou ainda como uma forma de resistência às rápidas mudanças da sociedade que passava a exigir novas necessidades e novos hábitos de trabalho.

O que se procurou mostrar no artigo foi que, na verdade, era justamente a incapacidade da agricultura de gerar emprego durante todo o ano que produzia um padrão particular de instabilidade e de mobilidade geográfica no mercado de trabalho rural. A mobilidade geográfica, inclusive, era um fenômeno que afetava não apenas a população brasileira. Pierre Denis observou que entre 40\% e 60\% dos colonos estrangeiros deixavam a fazenda dentro de um ano depois da chegada. De acordo com o autor, a ampla mobilidade era a característica mais marcante da vida rural em São Paulo e a instabilidade no trabalho causava uma série de problemas para os fazendeiros. (Denis, 1911, p. 206-207). O problema não era de escassez de mão-de-obra, mas a dificuldade de se obter uma oferta permanente de uma força de trabalho regular, no contexto da sazonalidade e instabilidade da economia rural em São Paulo da segunda metade do século XIX.

\section{BIBLIOGRAFIA}

Amaral, S. The rise of capitalism on the Pampas. The estancias of Buenos Aires, 17851870. Cambridge: Cambridge University Press, 1998.

Azevedo, C. M .M. Onda negra, medo branco. São Paulo: Paz e Terra, 1988.

Castro, H. M. de. Ao sul da história. São Paulo: Brasiliense, 1987.

. Das cores do silêncio. Os significados da liberdade no sul escravista, Brasil, século XIX. Rio de Janeiro: Arquivo Nacional, 1995. 
Cechin, J. A construção e operação das ferrovias no Brasil no século XIX. 1978. Dissertação (Mestrado), Unicamp. Campinas.

Costa, W. P. Ferrovias e trabalho assalariado em São Paulo. 1976. Dissertação (Mestrado), Unicamp. Campinas.

Dean, W. Rio Claro.Um sistema de grande lavoura, 1820-1920. Rio de Janeiro: Paz e Terra, 1977.

Ducker, J. H. Men of the steel rails. Workers on the Atchison, Topeka \& Santa Fe Railroad, 1869-1900. Lincoln: University of Nebraska Press, 1983.

Eisenberg, P. L. Homens esquecidos. Escravos e trabalhadores livres no Brasil, séculos XVIII e XIX. Campinas: Unicamp, 1989.

El-Kareh, C. Filha branca de mãe preta: a companhia de Estrada de Ferro D. Pedro II, 1855-1865. Petrópolis: Vozes, 1982.

Faria, S. de C. A colônia em movimento. Fortuna e família no cotidiano colonial. Rio de Janeiro: Nova Fronteira, 1998.

Franco, M. S. Homens livres na ordem escravocrata. São Paulo: Editora Unesp, 1997.

Kowarick, L. Trabalho e vadiagem: a origem do trabalho livre no Brasil. São Paulo: Brasiliense, 1987.

Klein, H. Nineteenth-century Brazil. In: Cohen, D. W.; Greene, J. P. (org.), Neither slave nor free. The freedmen of African descent in the slave societies of the New World. Baltimore e Londres: The John Hopkins University Press, 1972. p. 309-334.

Lamounier, M. L. Da escravidão ao trabalho livve. A lei de locação de serviços de 1879. Campinas: Papirus, 1988.

. Between slavery and free labour. Patterns of slave emancipation in Brazil and Cuba, 1830-1888. 1993. Tese (Doutorado), Universidade de Londres. Londres.

. Ferrovias, agricultura de exportação e mão-de-obra no Brasil no século XIX. História Econômica \& História de Empresas, III.1, p. 43-76, 2000.

Leff, N. H. Economic development in Brazil, 1822-1913. In: Haber, S. (org.), How Latin America fell behind. Essays on the economic histories of Brazil and Mexico, 1800-1914. Stanford: Stanford University Press, 1997, p. 34-64.

Licht, W. Working for the railroad. The organisation of work in the nineteenth century. Princeton: Princeton University Press, 1983.

Martins, J. S. M. O cativeiro da terra. São Paulo: Hucitec, 1990.

Mattoon, R. H. Railroads, coffee and the growth of big business in São Paulo, Brazil. Hispanic American Historical Review, LVII, 2, 2, p. 273-295, 1977.

Moura, D. A. S. Saindo das sombras. Homens livres e pobres vivendo a crise do trabalho escravo. Campinas, 1850-1888. 1996. Dissertação (Mestrado), FFLCH-USP. São Paulo. 
Saes, F. A. M. Estradas de Ferro e diversificação da atividade econômica na expansão cafeeira em São Paulo, 1870-1900. In: Szmrecsániy, T.; Lapa, J. R. A. (org.), História econômica da independência e do império. São Paulo: Hucitec/Fapesp, 1996, p. 177-196.

Souza, L. M. Os desclassificados do ouro. A pobreza mineira no século XVIII. Rio de Janeiro: Graal, 1982.

Taunay, A. F. História do café no Brasil. Rio de Janeiro: Dep. Nacional do Café, 1939, v. III, t. I.

FONTES

Manuscritas:

Arquivo Público do Estado de São Paulo. Manuscritos. Colônias. Ordem 7213, caixa (1827-1858), pasta Piracicaba, pasta Limeira.

Arquivo Público do Estado de São Paulo. Manuscritos. Solicitações de passagens ao Sr. Joaquim José do Rego Rangel, 1878. Ordem 7215, lata 3.

Impressas:

Brasil. Anais do Parlamento Brasileiro, ano 1882.

Brasil. Collecção das leis do Imperio do Brasil, 1879. Rio de Janeiro: Typ. Nacional, 1861-1880. v. 1879.

Congresso Agrícola. Collecção de documentos. Rio de Janeiro: Typ. Nacional, 1878.

Denis, P. Brazil. Transl. B. Mill. Londres: T. Fisher Unwin, 1911.

Discurso com que o Illmo. Excmo. Sr. Senador José Joaquim Fernandes Torres, presidente da provincia de São Paulo, abrio a Assembléa Legislativa Provincial, 1859. São Paulo: Typ. Joaquim Azevedo Marques, 1859.

Discurso com que o Illmo. Excmo. Sr. Senador José Joaquim Fernandes Torres abro a Assembléia Legislativa Provincial de São Paulo, 1860. São Paulo: Typ. Joaquim Roberto de Azevedo Marques, 1860.

Fox, D. M. Description of the line and the works of the São Paulo Railway in the Empire of Brazil: with an abstract of the discussion upon the paper (Minutes of the Institution of civil Engineers). London: William Clowes and Sons, 1870.

Godoy, J. F. de. A província de São Paulo. Trabalho estatístico, histórico e noticioso. [1 $1^{\mathrm{a}}$. ed.1875] São Paulo: Governo do Estado, 1978.

Grã-Bretanha. Parliamentary Papers, anos 1865, 1881. 
Relatório do Ministerio da Agricultura, Commercio e Obras Publicas. Rio de Janeiro: Typ Americana, 1879.

Soares, S. F. Notas estatísticas sobre a produção agricola e carestia dos gêneros alimentícios no Império do Brasil. [1 $1^{\mathrm{a}}$. ed. 1860] Rio de Janeiro: IPEA/INPES, 1977.

Tschudi, J. J. Viagem às provincias do Rio de Janeiro e S. Paulo. São Paulo: Martins, 1953.

Periódicos:

Railway Times, anos 1859, 1860

Herapath, anos 1862, 1863 